\title{
Influence of wood properties and bonding parameters on bond durability of European Beech (Fagus sylvatica L.) glulams
}

\author{
Denny OHNESORGE ${ }^{1 *}$, Klaus RICHTER ${ }^{2}$, Gero BECKER $^{1}$ \\ ${ }^{1}$ Albert-Ludwigs-University of Freiburg, Institute of Forest Utilization and Work Science, Werthmannstr. 6, 79085 Freiburg, Germany \\ ${ }^{2}$ Empa, Swiss Federal Laboratories for Materials Testing and Research, Wood Laboratory, Überlandstrasse 129, 8600 Dübendorf, Switzerland
}

(Received 23 June 2009; accepted 27 November 2009)

\author{
Keywords: \\ adhesion / \\ glulam / \\ delamination / \\ melamine-urea-formaldehyde / \\ Fagus sylvatica L.
}

\begin{abstract}
- Considerable progress has been made recently to promote glue-laminated beams of European beech (Fagus sylvatica L.) for load-bearing structures in engineering. However, further investigations into the bond durability are required. The objective of the present study was to analyse material and manufacturing factors and their combination to improve the resistance in delamination tests as required for the use in building service class 1 .

- In the experimental work, the influence of selected wood properties, manufacturing conditions, and the effect of a hydroxy-methylated resorcinol primer on the delamination resistance of beech glulams bonded under laboratory and industrial conditions with a melamine-urea-formaldehyde adhesive were investigated.

- The highest delamination resistance of the laboratory samples was achieved with the smallest lamellae thicknesses of $29 \mathrm{~mm}$. A closed assembly time of more than $30 \mathrm{~min}$ and the use of the primer further enhanced the bond durability. Higher delamination rates observed in glulams manufactured industrially were related to the relatively thick $(38 \mathrm{~mm})$ and often twisted beech lamellae used.

- The results suggested that bond durability required for service class 1 can be attained by restricting lamella thickness in beech glulam to a maximum of $30 \mathrm{~mm}$ and by using a minimum closed assembly time of $40 \mathrm{~min}$.
\end{abstract}

\section{INTRODUCTION}

Motivated by forest inventory reports identifying a growing amount of large-sized beech trees in central Europe, more effort has been made in the past decade to develop innovative products and markets to increase beech wood use. This has led to investigations into additional potential uses of beech, in particular the use of glue-laminated (glulam) beech beams in construction. Although, already in the mid-sixties, Egner and Kolb (1966) and later Gehri (1980) demonstrated the high strength of beech glulam beams so far their use has been limited, e.g. to pressure-treated, glued structural elements in wooden bridge and roof construction. The lack of standards for grading beech lamellae strength, and the absence of design values needed in construction design has restricted beech glulam use to date. Consequently, a number of investigations have focussed again on assessing the essential structural characteristics of beech timber, including strength, finger-joint strength, bonding performance, and the influence of red heartwood on glue line strength (Aicher and Reinhardt, 2007; Aicher et al., 2001; Blaß et al., 2005; Frühwald et al., 2003; Glos and Lederer, 2000; Ohnesorge et. al., 2006, 2008; Pöhler et al., 2006). The investigations conducted by Glos and Lederer (2000) and Blaß et al. (2005), which form the basis of the impending gen-

*Corresponding author: institut@fobawi.uni-freiburg.de eral building approval guidelines by the German Institute of Civil Engineering in Berlin (Z-9.1-679, Deutsches Institut für Bautechnik, 2009), in particular, have recommended beech glulam beams as a reliable, versatile construction product for use in moderate climates specified as service class I according to EN 1995-1-1:2004.

One major challenge is to ensure that beech glulam bond integrity, especially bond durability, is adequate. Studies on the short-term strength of defect-free, standardised specimens have revealed a variety of suitable adhesive types. These tests have shown that the short-term strength of test specimens, unaged prior to testing, was not affected sufficiently by adhesive type, amount of red heartwood (a species-inherent discoloration) or steaming level of the lamellae (Frühwald et al., 2003; Ohnesorge et al., 2006; Pöhler et al., 2006). Indeed, the longitudinal tensile shear strength tests carried out on structural adhesives before their approval and classification (EN 301:2006) must be conducted using beech timber. However, in Germany, no structural adhesive has been approved recently for beech glulam production. This is due to the poor performance of beech glulams bonded with different adhesives in the obligatory accelerated tests, especially in delamination tests (Aicher and Reinhardt, 2007; Frühwald et al., 2003). The limited use of beech glulams in the past means knowledge of the glue bond durability in the long-term has not been acquired. 
Preliminary tests from Frühwald et al. (2003) simulating midterm use revealed considerable delamination of test beams exposed to conditions comparable to service class II of EN 19951-1:2004 over a period of 30 weeks. Furthermore, less delamination was observed in beams stored in an attic. Whereas Frühwald et al. (2003) found lamella thickness and the manner of cutting lamellae (flat-sawn or quarter-sawn) affected delamination, Aicher and Reinhardt (2007) showed that the amount of red heartwood present, lamella width and closed assembly time primarily influenced delamination.

The difficulty of gluing high-density hardwoods is generally recognised, and the inadequate bonding performance found is thought to be caused by the presence of extractives as well as the frequently lower wettability of hardwoods (Vick, 1999; Zeppenfeld and Grunwald, 2005). Since beech wood glulams performed satisfactorily in dry strength tests, it seems likely that wood moisture changes occurring in accelerated delamination tests also may directly affect bonding performance. Although not only wood swelling affects bond durability, it often initiates bond failure (Frihart, 2005; 2009). Frihart (2009) recently put forward the theory that bondline durability is related to strain on the glue line caused by wood swelling. The internal swelling forces, which, according to Molinski and Raczkowski (1988), can reach up to 8 MPa for beech wood, could weaken the bond even if it were not large enough to cause bond fracture. Thus, stabilising the wood tissue at the bond interface may enhance bonding performance. For yellow poplar, Hofferber et al. (2006) showed that the acetylation of wood reduces swelling strain in all orthogonal directions. The dimensional stabilisation of the acetylated wood was thought to reduce glue line stress when wood moisture content changed, resulting in larger shear strength measurements than for untreated wood. Vick et al. (1995) proposed another method for enhancing the durability of bonds between wood and adhesives that uses the primer hydroxy-methylated resorcinol (HMR) to pre-treat Sitka spruce wood before bonding. Later, Vick (1997) and Richter (1999) conducted delamination tests demonstrating an improvement in bonding with different adhesives for various wood species when the wood surfaces were primed with HMR beforehand. A novolak-version of the HMR-primer was equally efficient, overcoming the main limitations: the long periods between application and bonding (4 h), and the short pot-life (3-4 h) (Christiansen 2005; Christiansen et al., 2003; Eisenheld and Gardner, 2005). Recently, López-Suevos and Richter (2009) successfully applied both the original HMR and the novolak-HMR to Eucalyptus globulus wood, a high-density wood that is difficult to glue. One theory to explain why the HMR-primer increases bond durability is that HMR prevents water from swelling amorphous regions by creating covalent cross-linking and thereby reducing the likelihood of interfacial failure and other mechanical stresses (Sun and Frazier, 2005).

These previous studies suggest that delamination resistance in beech glulam could be improved by considering specific wood substrate parameters and the bonding procedure. Thus, the objective of this study was to determine the extent to which the delamination resistance of beech glulam bonded with a melamine-urea-formaldehyde adhesive is influenced by spe- cific wood properties, manufacturing techniques and using the HMR-primer.

\section{MATERIALS AND METHODS}

\subsection{Experimental design}

In this study, experimental data were obtained from glulam beams produced in two different batches with different cross-sectional shapes (Tab. I). Series 1 to 3 consisted of 32 small glulam beams up to $1.2 \mathrm{~m}$ in length comprising 6 lamellae 29,35 , or $38 \mathrm{~mm}$ thick manufactured in the laboratory and subsequently termed laboratory beams (Henning, 2007; Ohnesorge et al., 2008). Series 4 consisted of $144.0 \mathrm{~m}$ long component-sized I-beams comprising 16 lamellae $38 \mathrm{~mm}$ thick manufactured industrially; subsequently termed industrial beams (Ohnesorge et al., 2008).

\subsection{Glulam manufacture}

All glulam beams were manufactured from boards sawn from beech logs with different amounts of red heartwood purchased at a local hardwood sawmill. The boards, initially about $56 \mathrm{~mm}$ thick, were kiln-dried to an equilibrium moisture content of $10 \pm 2 \%$ and then cut into lamellae of about $130 \mathrm{~mm}$ width and with lengths between $1.1 \mathrm{~m}$ and $4.9 \mathrm{~m}$. The lamellae of the laboratory beams were crosscut to $0.6-1.2 \mathrm{~m}$ lengths, conditioned in a climate of $20{ }^{\circ} \mathrm{C}$ and $65 \%$ relative humidity (RH) (subsequently standard climate), and planed 6 to $24 \mathrm{~h}$ before bonding. The industrial beams were produced under conditions outlined in Table I and described in detail in Aicher and Ohnesorge (2009). In contrast to the relatively short laboratory beam lamellae, most of the industrial beam lamellae revealed distortions, mostly twisting, along the entire $4 \mathrm{~m}$ length. Once the beam was assembled, pressure was applied to the glulams by screw-presses (up to $0.8 \mathrm{~N} / \mathrm{mm}^{2}$ ) to straighten the twisted, typically stiff beech lamellae to facilitate near complete joint closure.

\subsubsection{Adhesive and bonding procedure}

In beam manufacture, a commercial, water-soluble, two component melamine-urea-formaldehyde adhesive (MUF; Kauramin 681 with hardener 686; Türmerleim $\mathrm{GmbH}$ ) which meets the EN 301:2006 adhesive type I and II requirements was used in beam manufacture (Tab. I). The adhesive was applied at 220 to $250 \mathrm{~g} / \mathrm{m}^{2}$ to each lamella surface of the laboratory beams with a spatula, and the industrial beams with a semi-automatically roller. The mass of the adhesive applied to the laboratory beams was determined directly by comparing the lamellae weight before and after adhesive application. For the industrial beams, the mass of the adhesive was estimated by comparing the weight of the adhesive container before and after application.

The maximum possible open assembly time (subsequently max $O A T$ ), defined as the time from spreading the adhesive to lamellae surface until the end of adhesion ability, was determined by the DIN 68141:1995 thumb test. The max OAT ranged from 65 to $180 \mathrm{~min}$, since the effective manufacturing conditions differed for each series. The actual $O A T$ was less than 5 min for each beam. The actual closed 
Table I. Experimental design with data source and manufacture conditions.

\begin{tabular}{|c|c|c|c|c|}
\hline Specification & Series 1 & Series 2 & Series 3 & Series 4 \\
\hline Beam manufacture & Laboratory & Laboratory & Laboratory & Industrial \\
\hline No. of lamellae and thickness & $6 \times 29 \mathrm{~mm}$ & $6 \times 35 \mathrm{~mm}$ & $6 \times 35(38) \mathrm{mm}$ & $16 \times 38 \mathrm{~mm}$ \\
\hline $\begin{array}{l}\text { Cross-sectional d mensions } \\
\text { (all in mm) of the beams and } \\
\text { delamination test specimens }\end{array}$ & 29 & 310 & (120) & (604 \\
\hline Total beams/specimens/bonds & $8 / 16 / 80$ & $8 / 16 / 80$ & $8(8) / 16(16) / 80(80)$ & $14 / 14 / 210$ \\
\hline Beams with additional treatment & 4 primed with HMR & None & 8 primed with HMR & None \\
\hline Adhesive type & \multicolumn{4}{|c|}{ Melamine-urea-formaldehyde adhesive, Kauramin $683 / 688$} \\
\hline Adhesive/hardener (ratio) & $5: 1$ & $5: 1$ & $2: 1$ & $2: 1$ \\
\hline Adhesive application & Manually both-sided & Manually both-sided & Manually both-sided & Semi-automatically both-sided \\
\hline Amount per side (total) & $220(440) \mathrm{g} / \mathrm{m}^{2}$ & $250(500) \mathrm{g} / \mathrm{m}^{2}$ & $250(500) \mathrm{g} / \mathrm{m}^{2}$ & $240(480) \mathrm{g} / \mathrm{m}^{2}$ \\
\hline Climate conditions & $23{ }^{\circ} \mathrm{C} / 45 \% \mathrm{RH}$ & $20{ }^{\circ} \mathrm{C} / 60-70 \% \mathrm{RH}$ & $24{ }^{\circ} \mathrm{C} / 40 \% \mathrm{RH}$ & $20{ }^{\circ} \mathrm{C} / 60-70 \% \mathrm{RH}$ \\
\hline Wood moisture content & $12.9 \pm 0.4 \%$ & $11.4 \pm 0.7 \%$ & $12.4 \pm 0.5 \%$ & $12.1 \pm 1.4 \%$ \\
\hline $\begin{array}{l}\text { Open/closed acc. DIN } 68141 \\
\text { Assembly time realized }\end{array}$ & $\begin{aligned} & 65 / 65 \mathrm{~min} \\
< & 5 / 20 \text { to } 65 \mathrm{~min}\end{aligned}$ & $\begin{aligned} & 180 / 180 \min \\
< & 5 / 10 \text { to } 160 \mathrm{~min}\end{aligned}$ & $\begin{aligned} & 65 / 65 \mathrm{~min} \\
< & 5 / 10 \text { to } 35 \mathrm{~min}\end{aligned}$ & $\begin{array}{l}110 / 110 \mathrm{~min} \\
<5 / 30 \text { to } 50 \mathrm{~min}\end{array}$ \\
\hline $\begin{array}{l}\text { Pressure (press time) } \\
\text { Post-curing time }\end{array}$ & $\begin{array}{l}1.2 \mathrm{~N} / \mathrm{mm}^{2}(20 \mathrm{~h}) \\
>7 \text { days }\end{array}$ & $\begin{array}{l}1.2 \mathrm{~N} / \mathrm{mm}^{2}(>18 \mathrm{~h}) \\
>7 \text { days }\end{array}$ & $\begin{array}{l}1.2 \mathrm{~N} / \mathrm{mm}^{2}(20 \mathrm{~h}) \\
>7 \text { days }\end{array}$ & $\begin{array}{c}1.1 \mathrm{~N} / \mathrm{mm}^{2}(>18 \mathrm{~h}) \\
>40 \mathrm{~d}\end{array}$ \\
\hline
\end{tabular}

assembly time (subsequently $C A T$ ), defined as the time from assembly until full pressure application, varied within beams (a few seconds) and between beams (up to several minutes) due to the successive lamination assembly process of the beams. The $C A T$ ranged from 10 to $160 \mathrm{~min}$. An absolute pressure of about $1.2 \mathrm{~N} / \mathrm{mm}^{2}$ was applied to the laboratory beams in a semi-automatic press. An effective pressure of approximately $1.1 \mathrm{~N} / \mathrm{mm}^{2}$ was applied to the industrial beams by screw-presses using a dynamometric screwdriver. The pressure was maintained for at least $18 \mathrm{~h}$. To achieve full strength, all glulams were conditioned at standard climate for at least $14 \mathrm{~d}$ before cutting the beams into test specimens.

\subsubsection{HMR-primer}

To enhance the performance of the MUF adhesive under wet test conditions, and delamination tests in particular, the hydroxymethylated resorcinol (HMR) primer was used to stabilise the adherend surface. For twelve beams with lamella thicknesses of $t_{\text {lam }}=29,35$, and $38 \mathrm{~mm}$, the lamellae were planed and then pretreated with $150 \mathrm{~g} / \mathrm{m}^{2}$ of HMR-solution. This primer is an aqueous alkaline mixture consisting of $90.43 \%$ deionised water, $3.34 \%$ crystalline resorcinol, $3.79 \%$ formaldehyde (37\%) and $2.44 \%$ sodium hydroxide, which corresponded with the chemical composition of the original HMR-primer used by Vick et al. (1995). After the required reaction time of $4 \mathrm{~h}, 0.5 \%$ sodium dodecyl sulphate was added to the compound to wet the wood surface and assist penetration. The primed surfaces were then dried for approximately $10 \mathrm{~h}$ at $20 \pm 2{ }^{\circ} \mathrm{C}$ and $65 \pm 5 \% \mathrm{RH}$ before bonding.

\subsection{Specimen preparation and testing}

To assess the bonding performance, EN 392:1996 block shear, and EN 391:2002 procedure C delamination tests designed for daily quality control were used in this study. After beam curing and conditioning, full-cross-sectional slats, preferably free of defects, were cut out of the beams. For the industrial beams, they were cut at a distance of at least $100 \mathrm{~mm}$ from the end of the component-sized beams. Where knots or cracks most likely influenced glue line failure in industrial beams, the data were excluded from further analysis.

\subsubsection{Delamination}

Glulams were tested using the EN 391:2002 delamination procedure C specified for EN 1995-1-1:2004 service class I (indoor constructions). The tests were performed, in accordance with EN 386:2002 and EN 391:2002 regulations, on specimens $75 \mathrm{~mm}$ thick and with full cross-sectional dimensions of the beam (Tab. I). Before testing, the specimens were conditioned for 8 weeks in standard climate. The delamination specimens were vacuum-soaked in water at $85 \mathrm{kPa}$ for $30 \mathrm{~min}$, before being pressure-soaked at $550 \mathrm{kPa}$ for two hours. This cycle was repeated once. Then, the specimens were dried (Drying plant ULWA-E, Ulrich Lübbert Warenhandel $\mathrm{GmbH} \& \mathrm{Co}$. KG, Germany) for $90 \mathrm{~h}$ at $27.5^{\circ} \mathrm{C}$ and $30 \% \mathrm{RH}$. Afterwards, the delamination length was measured within an hour of the drying cycle in accordance with EN 391:2002 along the glue lines on each end-grain surface of each specimen. Two measurements defined in EN 391:2002, were carried out to assess the amount of delamination: first, the total delamination of a single specimen $\left(D_{\mathrm{S}}\right)$ was 
calculated, which expresses as a percentage the proportion of the delamination length $\left(l_{\mathrm{D}, \mathrm{S}}\right)$ of all glue lines to the total length of all glue lines of a specimen $\left(l_{\mathrm{S}}\right)$. Then, the delamination of the individual glue lines (bonds) $\left(D_{\mathrm{B}}\right)$ was calculated, representing the proportion of the delamination length on both end-grain surfaces $\left(l_{\mathrm{D}, \mathrm{B}}\right)$ of a glue line to the total length on both end-grain surfaces of the same glue line $\left(l_{\mathrm{B}}\right)$. These value were compared to the maximum allowable values for delamination stipulated in EN 386:2002 procedure $\mathrm{C}$ of 10\% for $D_{\mathrm{S}}$ and $40 \%$ for $D_{\mathrm{B}}$. Delamination was calculated using the following equations:

$$
D_{\mathrm{S}}(\%)=\frac{l_{\mathrm{D}, \mathrm{S}}}{l_{\mathrm{S}}} \cdot 100 \quad \text { and } \quad D_{\mathrm{B}}(\%)=\frac{l_{\mathrm{D}, \mathrm{B}}}{l_{\mathrm{B}}} \cdot 100 .
$$

\subsubsection{Block shear strength and wood failure}

Shear tests were performed on specimens with square shear areas $50 \mathrm{~mm}$ wide and thick, conforming to EN 392:1996. Before testing, the specimens were conditioned for 8 weeks in standard climate. Shear-strength testing was conducted in a Universal Testing Machine (Zwick 1474, Zwick GmbH \& Co. KG, Germany) with a constant crosshead displacement rate so that most failures occurred within $20 \mathrm{~s}$. The wood failure percentage $(W F P)$ was estimated on a 1:1 grid to the nearest percentage explored shear area.

The following measures of block shear tests were calculated and compared to the thresholds specified in EN 386:2002: the specimen mean and the minimum shear strength for the individual glue line, the mean $W F P$ of a specimen $\left(W F P_{\mathrm{S}}\right)$ and the individual $W F P$ of a single glue line (bond) $\left(W F P_{\mathrm{B}}\right)$. The minimal required $W F P$ was calculated in the following equations as defined in EN 386:2002:

$$
W F P_{\mathrm{S}}[\%]=144-9 \cdot f_{\mathrm{v}} \text { and } W F P_{\mathrm{B}}[\%]=153.3-13.3 \cdot f_{\mathrm{v}} \text {. }
$$

\subsection{Variables and statistical analysis}

The statistical analysis was performed for delamination resistance, shear strength, and WFP in laboratory beams. The analyses of variance (ANOVA) as well as the determination of factorial effects and their sizes were performed by means of a general linear model $(G L M)$. A replicate, sample 2, of all factorial combinations compared in the model was performed to verify the reliability of the conclusions drawn from the data of sample 1.

\subsubsection{Variables}

The model consisted of different factorial arrangements of the beam variables lamella thickness $\left(t_{\text {lam }}\right)$, closed assembly time $(C A T)$ class, and lamella pre-treatment (TREAT) as well as the variables red heartwood $(R H W)$ combination, growth ring angle (GRA), wood density $(W D)$, which were determined on each bondline.

Whereas variable $t_{\text {lam }}$ represented the three different lamellae thicknesses of 29, 35 and $38 \mathrm{~mm}$, variable TREAT accounted for primed or unprimed lamellae. The parameter $C A T$ was related to the individual maximum open assembly time (max $O A T)$ of each series, determined according to DIN 68141:1995 before bonding. The actual $C A T$ was expressed as proportion of the max $O A T$, enabling the comparison between the different series. For statistical analysis, the actual CAT was then classified into two classes: the "short" class included all beams with an actual CAT less than $50 \%$ of the max OAT.
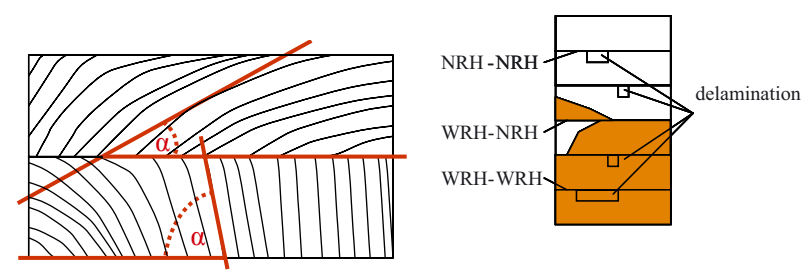

Figure 1. (a) Measurement and classification of growth ring angle: rift $=\alpha \leq 90^{\circ}$; half-rift $=\alpha \leq 60^{\circ}$; tangential $=\alpha \leq 30^{\circ}$ and $b$ ) red heartwood combinations ( $\mathrm{NRH}=$ no red heartwood; $\mathrm{WRH}=$ with red heartwood).

Accordingly, all specimens allocated an actual CAT of $50 \%$ or more were grouped into the $C A T$ "long" class.

The different manner of cutting the lamellae was considered in the model by including the variable GRA. GRA represented the growth ring angle $\alpha$ measured to the widest surface of the lamellae (faces) on the end-grain surface of the specimens (Fig. 1a). The measurements were subsequently separated into three classes: Angles with $\alpha$ from 60 to 90 degrees were classified into a "rift" class (R) representing growth rings running parallel to the edges (smallest surface of the lamella) or rectangular to the faces. Angles between $30^{\circ}$ and $60^{\circ}$ were classified as "half-rift" (HR), and the "tangential" class (T) denoted angels up to 30 degrees, in which the growth rings ran almost parallel to the faces.

Two different types of lamellae were used to analyse the influence of red heartwood $(R H W)$, measured according to DIN 4074-5:2003: firstly, lamellae with majority high red heartwood amount on the gluing surface $(>75 \%)$ and secondly, lamellae with majority low red heartwood amount on the gluing surface $(<25 \%)$. Three different combinations of red heartwood were tested within a bond. Combination "NRH-NRH" referred to a bond formed with lamellae free of red heartwood. In contrast, the combination "WRH-WRH" consisted of two lamellae with red heartwood, whereas for combination "WRHNRH", one lamella with red heartwood was bonded with a lamella free of red heartwood (Fig 1a).

\subsubsection{Statistical analysis}

The general linear model (GLM) was performed to determine the effect size of both variables $t_{\text {lam }}$ and $C A T$, as well as to analyse additional factors influencing delamination resistance. In the given design, the specimens were not randomised in every between-subject factor. The model was performed with glue line as a within-subject factor and $t_{\mathrm{lam}} C A T$ and TREAT as between-subject factors. To determine the effect of between-subject factors, the influence of uncontrollable factors that may affect the delamination resistance of each glue line were eliminated. The factors $G R A$-, $R H W$-combination and $W D$ varied uncontrollable within a test specimen from bond to bond and were handled as repeated covariates in the GLM. GRA and WD occurred as a combined variable (one value for each lamination). In order to test a worst-case scenario, only the highest value of the WD, and lowest growth ring angle, representing tangential cut lamellae, was used. The factor $R H W$, a nominal scale variable, was transformed into dummy variables.

The repeated-measures ANOVA assumes that dependent variables are normally distributed within the groups and sphericity. Delamination and WFP-data in block shear tests were not normally 
Table II. Delamination and block shear test results of MUF bonds with reference to lamella thickness $\left(t_{\text {lam }}\right)$ and closed assembly time $(C A T)$ only unprimed specimens: maximum and mean delamination of specimens $D_{\mathrm{S}}$ and maximum delamination of individual bondlines $D_{\mathrm{B}}$.

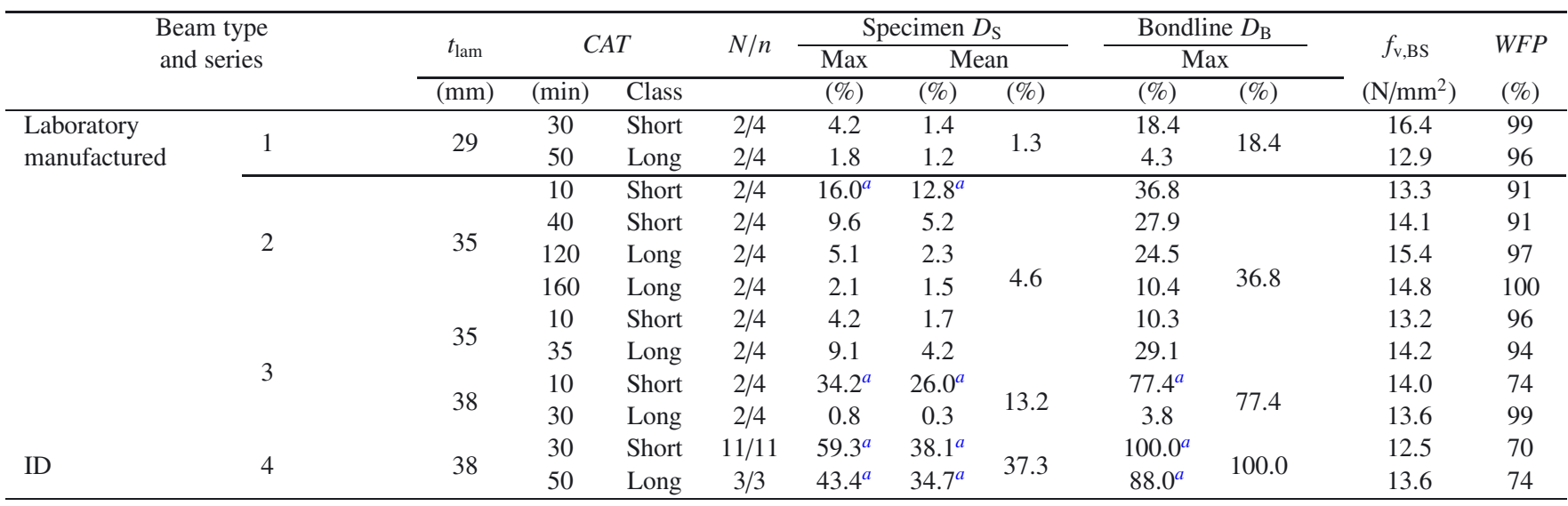

${ }^{a}$ Failed acc. to EN 386:2002; $f_{\mathrm{v}, \mathrm{BS}}=$ block shear strength; $W F P=$ wood failure percentage; ID = industrial manufactured; $N / n=$ number of beams $(N)$ and specimens $(n)$.

Table III. Effects of variables $t_{\mathrm{lam}}$ and CAT on delamination - results of the general linear model (repeated measure ANOVA) not involving covariates GRA, WD, RHW.

\begin{tabular}{|c|c|c|c|c|c|c|c|}
\hline Effects & Source & $\begin{array}{l}\text { Sum of } \\
\text { squares }\end{array}$ & $\begin{array}{l}\text { Degrees of } \\
\text { freedom* }\end{array}$ & $\begin{array}{l}\text { Mean } \\
\text { square }\end{array}$ & $\begin{array}{c}F \text {-value } \\
\text { sample } 1\end{array}$ & $\begin{array}{c}\text { Partial Eta } \\
\text { squared }\end{array}$ & $\begin{array}{l}F \text {-value } \\
\text { sample } 2\end{array}$ \\
\hline \multirow{4}{*}{ Between-subject } & $t_{\text {lam }}$ & 0.187 & 2 & 0.094 & $9.891^{* *}$ & 0.586 & $6.200^{* *}$ \\
\hline & $C A T$ & 0.240 & 1 & 0.240 & $25.343^{* *}$ & 0.644 & $13.909^{* *}$ \\
\hline & $t_{\mathrm{lam}} * C A T$ & 0.256 & 2 & 0.128 & $13.558^{* *}$ & 0.586 & $8.102^{* *}$ \\
\hline & Residual (bondline) & 0.132 & 14 & 0.009 & & & \\
\hline \multirow{3}{*}{ Within-subject } & Bondline & 0.014 & 1.995 & 0.007 & $0.326^{* * *}$ & 0.023 & $0.502^{* * *}$ \\
\hline & Bondline $* t_{\operatorname{lam}} * C A T$ & 0.061 & 3.989 & 0.015 & $0.719^{* * *}$ & 0.093 & $0.522^{* * * *}$ \\
\hline & Residual (bondline) & 0.593 & 27.925 & 0.021 & & & \\
\hline
\end{tabular}

* Degrees of freedom for between-subjects adjusted with Greenhouse-Geisser value of 0,442 ; sample 2 = replication - only $F$-value.

** Significant for $p<0.05$.

**** Not significant.

distributed. However, the $F$-test was used in this study to identify significant effects because it is remarkably robust in the event of deviations from normality distribution (Lindman, 1974). In cases where the Mauchly test showed violation of the sphericity assumption, the Greenhouse-Geisser value was applied to adjust the degrees of freedom in the averaged tests of significance. Pillai's criterion was used for multivariate tests since it is more robust when small sample sizes were tested, and therefore more appropriate than the commonlyused Wilks-Lambda. The relationship between specific variables was shown using Estimated Marginal Means (EMM) provided by the GLM. EMM are the means of the specified variables or interaction between variables adjusted for any other variables in the model.

\section{RESULTS}

\subsection{Decisive delaminating factors}

The results showed that the effect of lamella thickness $t_{\text {lam }}$ on delamination was significant, and more decisive than CAT.
The average delamination for glulam beams constructed from lamellae with $t_{\text {lam }}=29 \mathrm{~mm}$ was $1.3 \%$ compared to $4.6 \%$ for $t_{\text {lam }}=35 \mathrm{~mm}$ (Tab. II). The highest average delamination was observed for $t_{\text {lam }}=38 \mathrm{~mm}$, amounting to $13.2 \%$ for laboratory, and $37.3 \%$ for industrial beams. Delamination of beams with lamella thickness $t_{\text {lam }}=38 \mathrm{~mm}$ was higher in industrial beams than in laboratory beams. Even industrial beams in the $C A T$ "long" class reached an average delamination percentages of $D_{\mathrm{S}}=34.7 \%$ and $D_{B}=88 \%$. Moreover, several laboratory beam specimens in thickness class $t_{\text {lam }}=35$ and $38 \mathrm{~mm}$ exceeded the EN 386:2002 procedure C requirements either for the individual glue line $D_{\mathrm{B}}$, or the mean specimen $D_{\mathrm{S}}$ value. Only specimens with a lamella thickness of $29 \mathrm{~mm}$ met all requirements irrespective of $C A T$. However, several laboratory beams with lamella thicknesses of $38 \mathrm{~mm}$ passed the requirements when CAT was extended (class "long").

The analysis of the GLM results when covariates were omitted from the model (Tab. III) revealed that delamination resistance was influenced significantly, mainly by $t_{\mathrm{lam}}, C A T$ and 
Table IV. Effects of variables $t_{\mathrm{lam}}$ and CAT on delamination - results of the general linear model (repeated measure (M)ANOVA) including covariate GRA.

\begin{tabular}{|c|c|c|c|c|c|c|c|}
\hline Effect & Source & $\begin{array}{l}\text { Sum of } \\
\text { squares }\end{array}$ & $\begin{array}{l}\text { Degrees of } \\
\text { freedom* }\end{array}$ & $\begin{array}{l}\text { Mean } \\
\text { square }\end{array}$ & $\begin{array}{c}F \text {-value } \\
\text { sample } 1\end{array}$ & $\begin{array}{c}\text { Partial Eta } \\
\text { squared }\end{array}$ & $\begin{array}{c}F \text {-value } \\
\text { sample } 2\end{array}$ \\
\hline \multirow{5}{*}{ Between-subject } & $t_{\text {lam }}$ & 0.197 & 2 & 0.099 & $10.475^{* *}$ & 0.617 & $6.932^{* *}$ \\
\hline & $C A T$ & 0.062 & 1 & 0.062 & $6.571^{* *}$ & 0.336 & $2.720^{* * *}$ \\
\hline & $t_{\mathrm{lam}} * C A T$ & 0.266 & 2 & 0.133 & $14.125^{* *}$ & 0.685 & $8.885^{* *}$ \\
\hline & $G R A_{x}$ & 0.010 & 1 & 0.010 & $1.076^{* * *}$ & 0.076 & $1.262^{* * *}$ \\
\hline & Residual (bondline) & 0.122 & 13 & 0.009 & & & \\
\hline \multirow{4}{*}{ Within-subject } & bondline* $C A T$ & 0.036 & 1.769 & 0.021 & $0.861^{* * *}$ & 0.062 & $0.522^{* * *}$ \\
\hline & Bondline $* t_{\mathrm{lam}} * C A T$ & 0.053 & 3.537 & 0.015 & $0.625^{* * *}$ & 0.088 & $0.650^{* * *}$ \\
\hline & Bondline* $G R A_{x}$ & 0.044 & 1.769 & 0.025 & $1.033^{* * *}$ & 0.074 & $0.742^{* * * *}$ \\
\hline & Residual (bondline) & 0.550 & 22.993 & 0.024 & & & \\
\hline Multivariate $^{\dagger}$ & Bondline* $G R A_{x}$ & 0.861 & 15.436 & 4.000 & $10.000^{* *}$ & 0.861 & $10.000^{* *}$ \\
\hline
\end{tabular}

${ }^{*}$ Degrees of freedom adjusted for between-subjects with Greenhouse-Geisser value of 0.442 .

** Significant for $p<0.05$.

*** Not significant.

${ }^{\dagger}$ Pillai's trace; sample 2 = replication - only $F$-value presented; $G R A_{x}=$ growth ring angle at bondline position $x$.

their interaction $t_{\mathrm{lam}} * C A T$ (between-subject results in Tab. III). The effects of the independent variables $t_{\mathrm{lam}}$ and $C A T$ and their interaction was found to be significant. The variable CAT accounted for $64 \%$ of the variance (partial Eta-squared). The univariate pairwise comparison test showed that specimens bonded with lamellae $38 \mathrm{~mm}$ thick differed significantly from those with 29 and $35 \mathrm{~mm}$ thicknesses in all CAT classes. Significant differences could be observed between the $C A T$ "short" and "long" classes. The within-subject effects of the variables glue line, the interactions between glue line and $t_{\text {lam }}$ and $C A T$, and $t_{\text {lam }} * C A T$ proved statistically insignificant (within-subject factors Tab. III).

The replicate sample two supported the results obtained for the sample 1 except for the variable $C A T$ in the covariatecorrected model (Tab. IV). A subsequent pairwise comparison test revealed no significant differences between the samples.

\subsection{Delamination resistance affected by other factors}

The variables $G R A, W D$, and $R H W$ were analysed as covariates in the GLM. In contrast to WD and $R H W$, only GRA showed a significant (multivariate) interaction effect. Thus, only GRA was finally included as a repeated covariate in the model, producing a covariate-corrected model where the effects of $t_{\text {lam }}$ and $C A T$ as well as their interaction $t_{\mathrm{lam}}{ }^{*} C A T$ was again found to be significant, whereof the interaction effect accounted for $69 \%$ of the total variance (Tab. IV). The univariate pairwise comparison test conducted subsequently showed significant differences between the beams with $38 \mathrm{~mm}$ thick lamellae and the 29 or $35 \mathrm{~mm}$ thick lamellae.

\subsection{Influence of coupling agent}

All primed and unprimed specimens with lamella thicknesses of 29 and $35 \mathrm{~mm}$ met the recent EN 386:2002 specimen

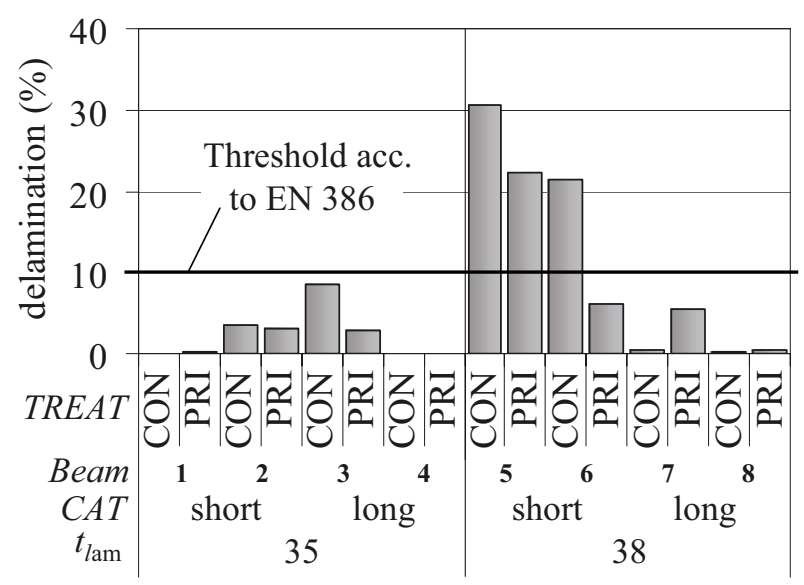

Figure 2. Average delamination $D_{\mathrm{S}}$ for primed (PRI) and unprimed $(\mathrm{CON})$ specimens with $t_{\mathrm{lam}}=35$ and $38 \mathrm{~mm}$.

mean and individual glue line requirements, except one primed specimen with lamella thicknesses of $29 \mathrm{~mm}$. Two unprimed beams and one primed beam with $t_{\text {lam }}=38 \mathrm{~mm}$ failed the specimen mean threshold test. A comparison of delamination tests of beams with $35 \mathrm{~mm}$ and $38 \mathrm{~mm}$ lamellae with, and without HMR-primer for each CAT class is shown in Figure 2. The results of the GLM analysis revealed that the effect of $C A T$ and $t_{\mathrm{lam}}$, and the interaction $t_{\mathrm{lam}} * C A T$ again were statistically significant (Tab. V). Figure 3a shows the predicted delamination of the statistical model for the lamellae pre-treatment in dependence on the CAT class, and irrespective of lamella thickness, whereas Figure $3 \mathrm{~b}$ shows the predicted delamination for the lamella thickness $t_{\text {lam }}$ in dependence on the variable TREAT, and irrespective of variable $C A T$ class. Although a considerable influence of the pre-treatment was observed, the effect of the HMR-primer was not proven statistically significant. 
Table V. Delamination of MUF adhesive on HMR-primed and unprimed beech laminations with reference to lamella thickness and closed assembly time.

\begin{tabular}{|c|c|c|c|c|c|c|c|c|c|c|}
\hline \multirow[b]{2}{*}{$\begin{array}{l}\text { Beam type } \\
\text { and series }\end{array}$} & & \multirow[b]{2}{*}{$\begin{array}{c}t_{\mathrm{lam}} \\
(\mathrm{mm})\end{array}$} & \multirow[b]{2}{*}{$\begin{array}{l}\text { CAT } \\
\text { class }\end{array}$} & \multirow{2}{*}{$N / n$} & \multicolumn{2}{|c|}{$\operatorname{Max} D_{\mathrm{S}}{ }^{a}$} & \multicolumn{2}{|c|}{ Mean $D_{\mathrm{S}}{ }^{a}$} & \multicolumn{2}{|c|}{$\operatorname{Max} D_{\mathrm{B}}{ }^{a}$} \\
\hline & & & & & $\mathrm{CON}$ & PRI & $\mathrm{CON}$ & PRI & $\mathrm{CON}$ & $\begin{array}{l}\text { PRI } \\
(\%)\end{array}$ \\
\hline \multirow[t]{6}{*}{ Laboratory } & \multirow[b]{2}{*}{1} & \multirow{2}{*}{29} & Short & $2 / 4$ & 4.2 & 10.9 & 1.4 & 5.1 & 18.4 & 43.0 \\
\hline & & & Long & $2 / 4$ & 1.8 & 1.8 & 1.2 & 0.6 & 6.1 & 4.4 \\
\hline & \multirow{4}{*}{3} & \multirow{2}{*}{35} & Short & $2 / 4$ & 16.1 & 4.4 & 6.6 & 1.6 & 36.8 & 12.4 \\
\hline & & & Long & $2 / 4$ & 9.1 & 3.4 & 2.7 & 1.4 & 29.1 & 17.1 \\
\hline & & \multirow{2}{*}{38} & Short & $2 / 4$ & 34.2 & 24.0 & 26.0 & 14.2 & 77.4 & 58.5 \\
\hline & & & Long & $2 / 4$ & 0.8 & 7.9 & 0.3 & 2.9 & 3.8 & 23.9 \\
\hline
\end{tabular}

${ }^{a}$ Maximum delamination acc. to EN 386:2002 procedure “C”: single specimen $D_{\mathrm{S}}=10 \%$; single glue line $D_{\mathrm{B}}=40 \%$.

$N / n=$ number of beams $(N)$ and specimens $(n)$.

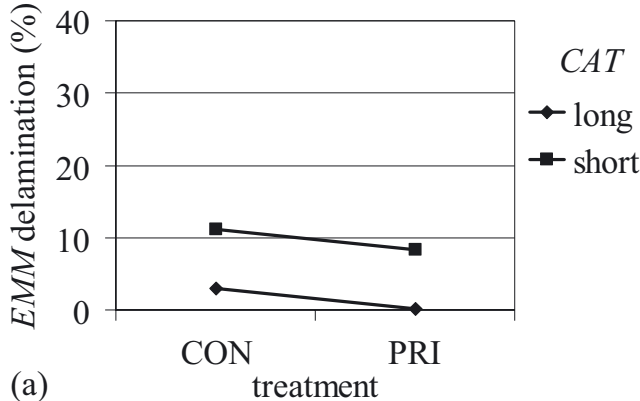

(a) treatment

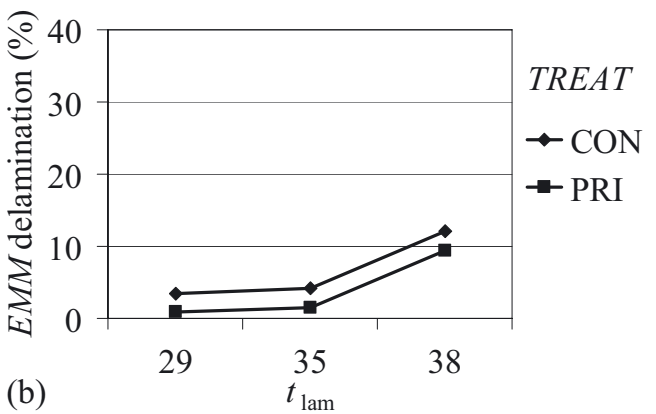

Figure 3. (a) Estimated marginal means $(E M M)$ of delamination regarding pre-treatment $(T R E A T:$ PRI $=$ primed; CON = unprimed control) and closed assembly time $(C A T)$, irrespective of the lamella thickness $\left(t_{\mathrm{lam}}\right)$. (b) EMM of delamination regarding $t_{\mathrm{lam}}$ and $T R E A T$, irrespective of $C A T$.

\subsection{Block shear tests}

Shear tests performed on standardised specimens according to EN 392:1996 revealed a mean block shear strength of $f_{\mathrm{v}, \mathrm{BS}}=14.0 \mathrm{~N} / \mathrm{mm}^{2}$ corresponding to an average $W F P$ of $93 \%$. The block shear strength of the individual specimens ranged from 6.7 to $19.5 \mathrm{~N} / \mathrm{mm}^{2}$, and the $W F P$ from 18 to $100 \%$ respectively. All laboratory beams met the EN 386:2002 requirements for individual shear strength of $f_{\mathrm{v}}=6.0 \mathrm{~N} / \mathrm{mm}^{2}$ and mean wood failure percentage $\left(W F P_{\mathrm{S}}\right)$. Two beams failed due to low individual wood failure percentages for the glue line $W F P_{\mathrm{B}}$. The block shear strength $f_{\mathrm{v}, \mathrm{BS}}$ and average WFP for the industrial beams, $12.8 \mathrm{~N} / \mathrm{mm}^{2}$ and $71 \%$ respectively, were significantly lower than laboratory beam measures (Tab. VI). The individual block shear strength ranged from 6.3 to $18.3 \mathrm{~N} / \mathrm{mm}^{2}$, and the $W F P_{\mathrm{B}}$ from 1 to $100 \%$. All industrial beams fulfilled recent mean $W F P_{\mathrm{S}}$ and individual glue line strength requirements, yet 20 glue lines failed individual glue line $W F P_{\mathrm{B}}$ threshold tests. The average values of shear strength and $W F P$ of all glue lines that failed were $10.5 \mathrm{~N} / \mathrm{mm}^{2}$ and $18 \%$ respectively, with a corresponding average delamination of $62 \%$. Again, the red heartwood amount affected neither the dry block shear strength nor the WFP. Furthermore, no significant influence of CAT was detected. No correlation (Spearman's rho rank-order correlation coefficient) was found between block shear strength and mean specimen delamination $\left(D_{\mathrm{S}}\right)$, whereas, significant mostly medium and negative correlations with coefficients between -0.35 and -0.70 could be observed between WFP and delamination in all beam series and for all lamella thickness classes.

\section{DISCUSSION}

In general, following aspects must be considered for a statistical analysis of the glued specimens: glulam beams are formed from more than two lamellae and have therefore more than one glue line. The shared lamella of two neighbouring glue lines affects the performance of both glue lines, which could cause correlated variables. The glue lines within a specimen are therefore matched or repeated in a statistical sense and must be recognized as inter-dependent variables. Thus, it is referred to as within-subject design or repeated measures design. Further analysis indicated that variables, other than $t_{\mathrm{lam}}$ and $C A T$, may affect the delamination resistance of beech wood laminations. In particular, the scatter of single glue line delamination results for thicker lamellae was considerably high, even for a longer $C A T$. Therefore, the variables GRA,WD and $R H W$ were analysed as covariates in the GLM to eliminate their effect on the model and to gain covariate corrected results.

\subsection{Delamination resistance}

By restricting lamella thickness to a maximum of $30 \mathrm{~mm}$, the delamination results of beech glulams met the 
Table VI. Results of block shear tests (acc. to EN 392:1996) and delamination tests (acc. to EN 391:2002) for the industrial manufactured beams.

\begin{tabular}{|c|c|c|c|c|c|c|}
\hline \multirow{3}{*}{ Beam No. } & \multirow{3}{*}{$n^{*}$} & \multicolumn{3}{|c|}{ Block shear strength $f_{\mathrm{v}, \mathrm{BS}}$} & \multirow{3}{*}{$\begin{array}{c}W F P_{\mathrm{S}} \\
(\%)\end{array}$} & \multirow{3}{*}{$D_{\mathrm{S}}$} \\
\hline & & Mean $\pm S D^{* *}$ & $C V$ & Min & & \\
\hline & & $\mathrm{N} / \mathrm{mm}^{2}$ & $\%$ & $\mathrm{~N} / \mathrm{mm}^{2}$ & & \\
\hline 1 & 14 & $13.6 \pm 2.6$ & 18.8 & 9.1 & 73 & 38 \\
\hline 2 & 15 & $12.8 \pm 2.8$ & 21.7 & 8.3 & 77 & 29 \\
\hline 3 & 15 & $13.2 \pm 1.8$ & 13.4 & 10.5 & 72 & 34 \\
\hline 4 & 15 & $11.8 \pm 2.2$ & 19.0 & 8.7 & 71 & 29 \\
\hline 5 & 14 & $11.8 \pm 2.3$ & 19.5 & 6.3 & 75 & 45 \\
\hline 6 & 14 & $12.5 \pm 2.5$ & 19.7 & 7.2 & 80 & 9 \\
\hline 7 & 13 & $13.1 \pm 1.8$ & 13.9 & 9.2 & 74 & 23 \\
\hline 8 & 14 & $12.6 \pm 2.3$ & 18.7 & 8.1 & 65 & 44 \\
\hline 9 & 15 & $13.6 \pm 1.9$ & 13.8 & 9.3 & 74 & 38 \\
\hline 10 & 15 & $14.6 \pm 1.7$ & 11.8 & 11.5 & 77 & 43 \\
\hline 11 & 15 & $14.2 \pm 1.8$ & 12.5 & 9.8 & 78 & 27 \\
\hline 12 & 15 & $11.6 \pm 2.0$ & 17.2 & 9.1 & 53 & 51 \\
\hline 13 & 15 & $12.7 \pm 2.3$ & 18.4 & 8.9 & 76 & 53 \\
\hline 14 & 15 & $11.3 \pm 1.9$ & 16.8 & 8.3 & 48 & 59 \\
\hline total & 204 & $12.8 \pm 2.3$ & 17.9 & 6.3 & 71 & 37 \\
\hline
\end{tabular}

* Number of bondlines; $f_{\mathrm{v}, \mathrm{BS}}=$ block shear strength; $W F P_{\mathrm{S}}=$ specimen mean wood failure percentage.

${ }^{* *}$ Minimum required shear strength $f_{\mathrm{v}}=6 \mathrm{~N} / \mathrm{mm}^{2}, D_{\mathrm{S}}=$ mean of specimens delamination.

EN 386:2002 requirements for adhesive type II. This effect of lamella thickness is in keeping with results reported by Frühwald et al. (2003), who analysed beams with lamella thicknesses of $t_{\mathrm{lam}}=18,24$, and $30 \mathrm{~mm}$ and found only specimens with $t_{\text {lam }}=18 \mathrm{~mm}$ passed the more rigorous EN 391:2002 procedure B delamination test. Following Friharts theory (2005), the noticeably high delamination rates observed on specimens with $38 \mathrm{~mm}$ thick lamellae may be related to increased wood swelling strains on the glue line compared to the strains, which occur in specimens with smaller lamellae. This could have weaken and finally fractured the bonds. In addition to lamella thickness, increasing the closed assembly time enhanced the delamination resistance of laboratory-manufactured beech glulams most effectively. This generally supports preliminary findings reported by Aicher and Reinhardt (2007), who conducted delamination tests using both EN 302-2:2004 procedures for adhesive type I and II. By extending either the open or closed assembly time a greater adhesive consistency is achieved and more adhesive can be absorbed into the lumen and cell walls than if pressure, which squeezes out most of the adhesive, is applied immediately preventing a sufficient amount from being absorbed into the wood substrate (Vick, 1999). Exceeding the maximum assembly time may cause the adhesive to dry out, or even precure before pressure is applied. Consequently, given that the maximum possible assembly time varies for different processing and substrate factors, it needs to be determined before bonding. Thus, recommendations for a maximum assembly time must be accompanied by specifications of adhesive type, wood moisture, and bonding conditions. Yet, the results of bonding tests conducted in this study suggest an assembly time of 20 to $40 \mathrm{~min}$ may be sufficient to account for delamination resistance.
The decisive influence of red heartwood reported by Aicher and Reinhardt (2007) was not observed in this study. Except $G R A$, neither $W D$ nor any other factor was found to affect delamination significantly in the statistical model. While these factors may enhance the delamination resistance, realistically they cannot be considered in manufacture of glulams.

The use of the primer HMR also has decreased delamination percentages. Although this was not found to be significant in our model, the primer together with an extended $C A T$, may allow the use of lamellae thicker than the $30 \mathrm{~mm}$ specified in current durability requirements. Because only the maximum $W D$ and the lowest GRA were considered as covariates in the model, the total size of their effect could not be ascertained.

The delamination test was developed and established to indicate the long-term performance of wood glue bonds, the appropriateness of applying this test method in general and to glulams made from hardwoods like beech in particular, has been discussed intensely (Aicher and Reinhardt, 2007; Frühwald et al., 2003; Wiegand and Schwaner, 2006). The species inherent low natural durability and rather high shrinkage/swelling coefficients restrict the use of untreated beech wood to service conditions typical in insulated heated rooms. Therefore, accelerated aging tests may be too harsh given that the tests involve rapid wetting and drying during which time little is known about the forces exerted on the glue line. Moreover, the representativeness of these tests in building up the forces arising in actual applications where stress is allowed to dissipate through stress relaxation of the wood is uncertain (Frihart, 2008). For beech glulams, there is virtually no experience about the long-term glue bond durability, why the suitability of delamination tests for assessing bonds durability has not been proven so far. Finally, the question of whether current tests are too harsh is more a legal than a technical 
one. Since one cannot ensure that indoor rooms will always be heated, indoor constructions should be able to withstand moderate humidity and temperature changes, which may occur temporarily. Therefore, the rather conservative delamination test appears to be the most suitable test method currently. Nevertheless, the long process duration of $96 \mathrm{~h}$ at least required for the EN 391:2002 delamination procedure $\mathrm{C}$ test is inconvenient for routine quality inspections during glulam production.

\subsection{Block shear tests}

In the EN 386:2002 regulations, either delamination tests under EN 391:2002 or block shear tests under EN 392:1996 are applicable for routine quality inspections of glulams intended for indoor construction (service class 1 in EN 19951-1:2004). However, sufficient block shear strength according to EN 392:1996 tests does not indicate necessarily that delamination occurs at an acceptable level. Shear strength tests are obligatory on dry specimens with a $50 \mathrm{~mm}$ squared shear cross-sectional area that are not aged with full cross-sectional beam dimensions prior to cutting and testing. Thus, shear tests prescribed in EN 392:1996 may be valid for identifying serious adhesion failures yet unsuited to determining bond durability in beech wood. This study supports recommendations for delamination test rather than block shear tests for routine quality control. In addition, it appears that the glue line strength requirements presently specified in EN 386:2002 are too low (Aicher and Ohnesorge, 2009). In contrast, the wood failure percentage thresholds appear too harsh; the individual wood failure percentage $W F P_{\mathrm{B}}$ was not attained in many cases, even for several beams produced under optimal laboratory conditions. The equation specified recently in EN 386:2002 does not appear to be adaptable to beech glulams.

\subsection{Industrial glulam manufacture}

Generally, the industrially manufactured glulams showed more delamination than laboratory beams with same lamellae thicknesses of $t_{\mathrm{lam}}=38 \mathrm{~mm}$, even for those produced with longer CAT (class "long"). Since the manufacturing conditions of these beams were comparable to those produced in the laboratory, other factors may cause the weak bonding performance, for example the application of initial pressure during assembly to straighten their frequently twisted lamellae (see Sect. 2.2). This procedure may have led to an uneven distribution of pressure during glue line formation, and also may have squeezed out some adhesive before the final pressure was applied. Consequently, for several beams, the actual CAT was much shorter than the targeted $C A T$ and this may have caused the greater delamination observed. The distortion of beech lamellae may be reduced by adopting a lamella thickness $30 \mathrm{~mm}$ or less as already recommended. Furthermore, it may be advisable to extend the open assembly time to avoid problems with ensuring the closed assembly of twisted beech lamellae in industrial glulam production. In this case, a two-sided application of the adhesive appears necessary.

\subsection{Future research needs}

Under process conditions previously described sufficient glue line performance appears possible for beech glulams constructed from lamellae with a maximum thickness of $30 \mathrm{~mm}$. However, more research is needed into the practicability of extending the open or closed assembly time - for different lamellae thicknesses. Furthermore, an investigation of other adhesives and the use of the novolak version of the primer HMR should be undertaken, which overcomes the main limitations to using the original HMR-primer and creates opportunities for its industrial use. Finally, an accelerated test method needs to be found that considered the forces occurring under service conditions overcoming the difficulties associated with simulating conditions of beams under load. The test method should simulate moisture changes in tests specimens holding full cross-sectional beam dimensions to develop comparable stresses upon the glue line.

Acknowledgements: This study was performed at the Institute of Forest Utilization and Work Science, University of Freiburg under the EU-CRAFT project "Innovation for Beech" and the "large-sized timber" project funded by the German Federal Ministry of Education and Research (BMBF). Financial support provided by the European Commission as well as by the BMBF is gratefully acknowledged. Essential parts of the work were carried out at the Wood Laboratories of Empa (Swiss Federal Laboratories for Materials Testing and Research) in Duebendorf as well as at the Otto-Graf-Institute-MPA (Materials Testing Institute) of the Department of Timber Constructions, University of Stuttgart. We are extremely grateful to Burgbacher Holztechnologie $\mathrm{GmbH}$ for their invaluable support and preparedness to manufacture the industrial glulam beams essential to this study. We extend our thanks to Rüdiger Mutz, who provided support and advice for the statistical analysis of the data and we also thank Helen Desmond for the English correction and proofreading of the manuscript.

\section{REFERENCES}

Aicher S. and Ohnesorge D., 2009. Shear strength of glued laminated timber made from European Beech timber. Eur. J. Wood Prod. DOI 10.1007/s00107-009-0399-9 (in press).

Aicher S. and Reinhardt H.W., 2007. Delaminierungseigenschaften und Scherfestigkeiten von verklebten rotkernigen Buchenholzlamellen. Holz Roh. Werkst. 65: 125-136.

Aicher S., Höfflin L., and Behrens W., 2001. A study on tension strength of finger joints in beech timber laminations. Otto-Graf-J. 12: 169186.

Blaß H.J., Denzer J., Freese M., Glos P., and Linsenmann P., 2005. Biegefestigkeit von Brettschichtholz aus Buche. Forschungsbericht der Versuchsanstalt für Stahl, Holz und Steine, Abteilung Ingenieurholzbau. Universität TH Karlsruhe.

Christiansen A.W., 2005. Chemical and mechanical aspects of HMR primer in relationship to wood bonding For. Prod. J. 55: 73-78.

Christiansen A.W., Vick C.B., and Okkonen E., 2003. Development of a novolak-based hydroxmethylated resorcinol coupling agent for wood adhesives. For. Prod. J. 53: 32-38.

DIBt, 2009. Allgemeine Bauaufsichtliche Zulassung für Brettschichtholz aus Buche und Buche-Hybridträger. Zulassungsnummer: Z-9.1-679 Antragsteller: Studiengemeinschaft Holzleimbau e.V.

Eisenheld L. and Gardner D.J., 2005. Developing an industrial friendly process for hydroxymethyl resorcinol (HMR) priming of wood using a novolak-based HMR. Forest Prod. J. 55: 61-66. 
Frihart C.R., 2005. Adhesive bonding and performance testing of bonded wood products. J. ASTM Int. 2 (7).

Frihart C.R., 2009. Adhesive groups and how they relate to the durability of bonded wood. J. Adhes. Sci. Technol. 23: 601-617.

Frühwald A., Ressel J.B., and Bernasconi A., 2003. Hochwertiges Brettschichtholz aus Buchenholz. Bundesforschungsanstalt für Forst- und Holzwirtschaft Hamburg. Abschlussbericht: 181.

Gehri E., 1980. Möglichkeiten des Einsatzes von Buchenholz für Tragkonstruktionen. Schweiz. Bauwirtsch. 56: 17-21.

Henning M., 2007. Verklebungsversuche von Rotbuche (Fagus sylvatica L.) - Untersuchung der Klebefugenfestigkeit von unterschiedlich behandelten Rotbuchenlamellen. Diplomarbeit am Institut für Forstbenutzung und Forstliche Arbeitswissenschaften der Fakultät für Forst- und Umweltwissenschaften der Albert-LudwigsUniversität Freiburg i. Br.

Hofferber B.M., Kolodka E., Brandon R., Moon R.J., and Frihart Ch.R., 2006. Effects of swelling forces on the durability of wood adhesive bonds. Adhesion Society. In: Proc. meet. 29: 187-189. Jacksonville, Florida.

Lindman H.R., 1974. Analysis of variance in complex experimental designs. W.H. Freeman \& Co, San Francisco.

Lopez-Suevos F. and Richter K., 2009. Hydroxymethylated resorcinol (HMR) and Novolak-based HMR (n-HMR) primers to enhance bond durability of Eucalyptus globulus glulams. J. Adhes. Sci. Technol 23: 1925-1937.

Molinski W. and Raczkowski J., 1988. Mechanical stresses generated by water adsorption in wood and their determination by tension creep measurements. Wood Sci. Technol. 22: 193-198.

Ohnesorge D., Richter K., and Seeling U., 2006. Glueability of Beech wood containing red heartwood. Proc. 5th Int. Symp. Wood Structure and Properties, Sliac - Sielnica, Slovakia, pp. 471-474.

Ohnesorge D., Richter K., Becker G., and Aicher S., 2008. Adhesion behaviour of glued laminated timber from European Beech. Proceedings Final Conference COST E34 "Bonding of Timber Enhancing bond line performance", Sopron, Hungary.
Pöhler E., Klingner R., and Künniger T., 2006. Beech (Fagus sylvatica L.) - Technological properties, adhesion behaviour and colour stability with and without coatings of the red heartwood. Ann. For. Sci. 63: $129-137$.

Richter K., 1999. Feuchtebeständige Verklebung von Brettschichtholz durch den Einsatz eines Haftvermittlers. In: 5. Internationales Holzbau-Forum -IHF-, Holz, der universelle Verbundpartner. Congress-Zentrum Garmisch-Partenkirchen, $10 \mathrm{~S}$.

Sun N. and Frazier C.E., 2005. Probing the hydroxymethylated resorcinol coupling mechanism with stress relaxation. Wood Fiber Sci. 37: 673681 .

Türmerleim, 2005. Technisches Merkblatt BASF Kauramin ${ }^{\circledR}$ Leim 683 flüssig mit Kauramin ${ }^{\circledR}$ Härter 688 flüssig im Holzleimbau. Türmerleim GmbH, Ludwigshafen.

Vick C.B., 1996. Hydroxymethylated resorcinol coupling agent for enhanced adhesion of epoxy and other thermosetting adhesives to wood. In: Proc. Wood Adhes. 1995, Symp. Forest Prod. Soc., Madison, WI, pp. 47-55.

Vick C.B., 1997. Enhanced adhesion of melamine-urea and melamine adhesives to CCA-treated Southern Pine Lumber. For. Prod. J. 47: 83-87.

Vick C.B., 1999. Adhesive Bonding of Wood Materials. In: Wood handbook - Wood as an engineering material. Chap. 9: 1-24. Gen. Tech. Rep. FPL-GTR-113. Madison, WI US Department of Agriculture, Forest Service, For. Prod. Lab. 463 p.

Vick C.B., Richter K., River B.H., and Fried A.R., 1995. Hydroxymethylated resorcinol coupling agent for enhanced durability of bisphenol-A-epoxy bonds. Wood Fiber Sci. 27: 2-12.

Wiegang T. and Schwaner K., 2006. Brettschichtholz aus Buche oder anderen Laubhölzern. Proceedings "Laubholzkongress" 9th March 2006, Stuttgart-Hohenheim, Germany, 98 p.

Zeppenfeld G. and Grunwald D., 2005. Klebstoffe in der Holz- und Möbelindustrie. DRW-Verlag. Weinbrenner GmbH \& Co. KG, Leinfelden-Echterdingen, $352 \mathrm{p}$. 